\title{
Introduction: \\ Public policy at a crossroads
}

Public policy in Britain, as in other developed countries, faces severe challenges from many directions. The continuing economic crisis and its aftermath bring these issues to the forefront of public debate, but risk obscuring the underlying issues behind immediate political tussles over the recovery programme, constitutional reform, bankers' bonuses and other pressing questions.

This book tackles the basic questions that confront twenty-first-century policy-making in seven substantive chapters, each written by a leading expert in the field: finding a way forward for the British economy; the dilemma of coping with rising demand in the context of limited resources; how to respond to climate change; managing ethnic diversity as multiculturalism appears to have lost its way; whether demographic change equates with a growing burden of dependency; under what circumstances localism helps resolve concentrated neighbourhood problems; and how to overcome public disaffection with politics. A concluding chapter considers the more practical issue of developments in social science that might help it make a more forceful contribution to public policy.

The chapters analyse the contribution of social science to understanding the issues in each of these areas. They go on to review the range of possible developments in the medium-term future. We will first set out the contents of the individual chapters and then discuss the notion of policy paradigm that underlies the approach to the relationship between ideas and policy-making contained in them. We will move on to examine emerging themes in the relationship between government and other agencies bound up in policy-making, individual citizens, market actors and community activity, and conclude by reviewing the relationship between social science and public policy.

\section{The chapters}

The first substantive chapter, by Professor Andrew Gamble, is written as the British economy emerges unsteadily from the most serious recession since the 1930s. Professor Gamble argues that a political economy perspective is necessary to understand the debates surrounding economic growth. He reviews the way in which commentators have analysed the challenges facing public policy. He then examines debates about the crash and the deficit, the role and size of the state and the appropriate growth model. The major alternative approaches to growth currently under discussion lie between a return to the liberal financial model, dominant since the 1980s and sometimes termed 'privatised Keynesianism', and greater government intervention to restore the role of the manufacturing sector, possibly involving a shift to a more European-style corporatism. The chapter concludes by considering three scenarios: a return to growth; a shift in the international environment that renders austerity permanent; and the imposition of radical changes to curb expansion and cut back carbon emissions to sustainable levels.

Current demands to reduce the level of public debt draw attention to the insistent pressures on public spending. Population ageing and rising public expectations demand increases; the exigencies of international competitiveness, and now the 
economic crisis, require cutbacks. In the next chapter Professor Peter Taylor-Gooby reviews the range of strategies that have been developed to manage the dilemma between maintaining services and constraint including shifts in responsibility in various areas towards the market and the individual or voluntary sector, target-setting, manifold attempts to manage and restrain public provision, and attempts to change people's behaviour to cut demand. None of these approaches is entirely acceptable to public opinion and none has been markedly successful in solving the problem. This suggests that the dilemma of spending versus cutting will continue to underlie policymaking, that future policies must combine a range of approaches, and that greater attention to fostering a more informed and genuinely democratic debate is necessary so that new policy directions will be able to gain public support.

The challenge to current economic and social policies posed by climate change is more severe than in any other area. Chapter four by Professor Ian Gough reviews evidence on the nature of the problem, focusing particularly on debates about the impact on economic growth. He reviews current responses: that capitalist economies will find ways to cope with growing carbon emissions as they expand; that growth strategies compatible with environmental futures are possible; and that it is impossible to maintain growth rates and address the problem. He concludes that adequate and practicable responses cannot be generated within current policy frameworks. Current policies place too great an emphasis on economic incentives and fail to exploit the additional opportunities to reduce emissions through direct regulation or stronger leadership in cultural change.

The non-white population of European countries is small, rapidly growing and heavily concentrated, so that in many cities ethnic minority populations will grow rapidly towards 40 or 50 per cent within 40 years. This development poses major political and cultural challenges. In chapter five Professor Tariq Modood reviews the chief current policy responses - assimilation, integration and multiculturalism - in the context of claims by politicians in Germany, France and the UK that 'multiculturalism is dead'. He distinguishes between two multicultural approaches: a valuing of diversity which accords full recognition to differences between cultural groups within a liberal democratic framework; and a multiculturalism which values cultural interaction and social mixing but withholds institutional recognition from groups, especially religious ones. The first approach may unintentionally strengthen barriers between groups and foster segregation, whilst the second may marginalise certain cultural orientations and communities. Progressive policy-making must uphold individual rights and freedom to belong or not belong but it must not stigmatise or exclude groups from full participation in public life. The chapter concludes by analysing the emerging ethnic fault-lines across Europe and stresses the significance of a shift from colour to religion as the foundation of group identity, with major implications for the relationship between religion and politics.

In chapter six, Professor Pat Thane examines debates about future demographic patterns. She shows that the case for immediate cutbacks in spending and for the restructuring of pensions, health and social care to defuse a presumed 'demographic time-bomb' is not compelling. She goes on to examine alternative demographic scenarios and sets out some guidelines for policies to cope with future demographic change, recognising the contributions that older citizens can make to society. 
Building a 'Big Society' in which citizens would be empowered to deal with local issues is high on the political agenda. In chapter seven Professor Anne Power stands back from current debates in this field. She traces the origins of community politics in the co-operative institutions that people set up to manage the pressures and problems of eighteenth- and nineteenth-century industrialisation. Post-war debates in this country have been heavily influenced by US experience in the struggles for civil rights and in the Great Society programme. These led to the implementation of neighbourhood policies under both Labour and Conservative governments from the 1970s onwards. The key theme in all these developments has been the support and involvement of the state in enabling citizen's groups to operate effectively and in providing resources for them. Professor Power's analysis shows that Big Society is not an alternative to government but that, to be effective, the two must operate within a framework of mutual support.

The problems outlined in this book require new directions in policy-making if they are to be tackled effectively. Chapter eight by Professor Gerry Stoker sets out changes in UK political systems that will help to build public support for reforms. The current context is one of growing popular disaffection with politics. Professor Stoker reviews explanations of how this has come about: declining trust in politicians; the discrediting of political processes; and disappointment with the output in terms of policies and policy-thinking. He then considers solutions proposed by those who seek to reinvigorate representative institutions through such changes as greater use of proportional representation and more devolution of powers to local government, and those who wish to go further in supporting citizen activism and creating new opportunities for participation. He suggests that both approaches need to be combined.

The final chapter, by Professors Gerry Stoker and Peter Taylor-Gooby, returns to the question of how best social scientists can contribute to public policy. It discusses how both the policy-making process and the professional organisation of social science, as currently structured, militate against helpful interchange. This leads in two directions. First, it is desirable to open up the range of approaches and orientations available to policy-making, by ensuring that those involved are recruited from a wide range of communities, by analysing how policy objectives are selected and defined and by promoting greater interplay at different career stages between government and academic life.

Secondly, it is difficult to envisage radical changes in the operation of a system driven by the immediate and imperative demands of day-to-day government and by the concern of many politicians to gain and retain power through election. These issues take the centre of policy-making outside the remit of most academic work. For these reasons more weight must be placed on possible changes within social science. We suggest that social science needs to develop, alongside the academic research which is at its heart, a 'design arm' directed to practical issues and concerned with the application of research findings in improving policy outcomes.

The issues with which this book deals are fiercely debated across the policy community by academics, think-tanks, politicians and policy-makers. The objective is to stand back from the immediate debate and map out what social science has to offer to policy-makers and how best it may make that contribution. The analysis uses the notion of policy paradigm to understand how the range of viewpoints and approaches 
developed by academic commentators relate to the more concrete and focused conceptions of those engaged in practical policy-making.

\section{Paradigms and policy discourse}

A paradigm links together normative and descriptive elements, the former subject to dispute, the latter in principle empirically based, to provide a way of approaching a particular issue and of justifying that approach. Peter Hall explains the core idea in an influential paper as follows: 'policymakers customarily work within a framework of ideas and standards that specifies not only the goals of policy and the kind of instruments that can be used to attain them, but also the very nature of the problems they are meant to be addressing. Like a Gestalt, this framework is embedded in the very terminology through which policymakers communicate about their work, and it is influential precisely because so much of it is taken for granted and unamenable to scrutiny as a whole' (Hall 1993, 279). This perspective is widely used in the study of public policy-making.

The paradigm approach draws on the Kuhnian idea that progress in natural science takes place within paradigms in order to exploit the idea of paradigm revolution. Kuhn argued that scientists work within a paradigm - a framework of ideas that defines what is known, highlights areas for future work and explains why they are important (1962). So long as the paradigm proves fruitful, science develops within the framework. If research findings fail to fit the paradigm, the paradigm will be modified to accommodate the new material. Finally, it breaks down. A period of confusion follows. If alternative paradigms emerge, debates between them will provide an unstable structure. Eventually one will succeed, and 'normal' science, framed within a fresh paradigm, progress. Standard examples would be the Copernican revolution in astronomy or the Einsteinian revolution in physics.

Policy-making is not natural science and the term is used by analogy. Policy paradigms provide a framework of ideas that links together descriptive statements about the area of policy with normative statements about the goals of policy. They explain why some policies will achieve desired goals and others will not. Normal policy continues within the framework until it appears unsuccessful. There follow modification, confusion and opportunities for a new paradigm to emerge. Policy entrepreneurs within political parties, the world of think-tanks and lobby groups and the Whitehall community compete to offer one. Hall explains the shift between neoKeynesian economic management and monetarism in the 1980s as a paradigm shift. The experience of stagflation in the 1970s demonstrated the failure of interventionism. The government was unable to manage the economy successfully by using the available regulatory mechanisms. As a result a new approach was introduced, linked to the ideas associated with the radically reforming Conservative government elected in 1979 , (see Ch 2).

In the social world, in contrast to that of natural science, paradigm change is a political process. Different paradigms compete to explain developments and justify responses. For example, in the late 1970s, the Labour party pursued a reflationary state-centred alternative economic policy; other commentators promoted the European corporatist approach and the Conservative party spearheaded the monetarist paradigm. It is always possible that no new paradigm may emerge or that a paradigm shift may 
take place that does not enable policy to achieve the specified goals, so that the country fails to find a plausible route towards its economic goals as in Japan during the 'lost decade of the 1990s.

Disputes between proponents of different policy approaches are not easy to resolve. The political process tends to foreground particular paradigms that fit the prior assumptions of policy-makers and treat others as irrelevant. The paradigms dominant in each area frame policy thinking and delimit the range of possible solutions.

The first step in linking social science to policy-making is to recognise this point. In this book we review the policy paradigms that could be constructed on the basis of available social science knowledge and theory-building in the fields we discuss. We consider the relationship between these paradigms and public policies, and point out that many potential social science contributions fail to enter the policy arena. We call for openness to a wider range of viewpoints in tackling the problems that confront public policy. We also suggest that social scientists should develop a more consciously policy-oriented approach alongside their academic research, which would examine how this work might be applied to more practical issues. In each chapter we can identify a dominant paradigm that drives current policy, and also a range of available alternatives discussed by others. To summarise:

- The first substantive chapter discusses the range of approaches to the current economic crisis. It argues that a liberal financial paradigm, emphasising the role of private market actors, tends to predominate in current policy-making. It discusses the range of alternatives that posit a stronger role of government intervention or lean towards a more corporatist approach. These would rest on a broader political economy.

- In the second, on dilemmas facing public policy-makers, the dominant theme in current policy is of continuing austerity, following the evidence of increased demographic and other pressures on public spending and the likelihood that these will continue. A wide range of approaches to managing public provision exist, drawing on developments in management science, public administration, behavioural psychology and microsociology. Since none appears capable of solving the problem by itself and any new departures will require strong public support, future policies will require more open and serious public debate about the services government can offer.

- The third policy chapter, dealing with climate change, shows how current attempts to control carbon emissions rest heavily on economic incentives, following a rational actor model. Too little attention is paid to alternatives such as direct state regulation or changing behaviour by offering leadership in public opinion. These would rest on a broader political economy approach to the issue and require a more interventionist role from the state.

- The analysis of multiculturalism in the next chapter suggests that current approaches combine a degree of hostility to group-based multiculturalism with a certain degree of pragmatic corporatism in policies towards 
minorities with strong group identities. It argues that a more sophisticated approach to identity will not be based on an exclusively individualist paradigm but will prize individual agency as well as group belonging and embrace measures to promote individual as well as group rights.

- The discussion of demographic shifts in the following chapter analyses how policy-making tends to rest on the assumption that population ageing is problematic on the grounds that a growing proportion of dependent older people will require extra public spending so that current services become unsustainable. The chapter seeks to move beyond the economics of spending to include a broader and more sociological account of the contributions that older people make to society and of how these might be enhanced by a more supportive approach from government, mitigating the problem.

- Much of the debate about neighbourhood problems and the 'Big Society' conceives community activities as an alternative to government. This fails to take seriously the fact that the activities of individuals in communities have developed alongside the growth of the modern welfare state and how government intervention and support is essential to maintain successful local initiatives. An alternative approach requires a more complex model of community politics and of how actions at the individual and local level relate to the more top-down activities of government.

- Evidence of a growing mistrust of the political class, expressed in political disengagement (chapter eight) has led commentators to offer a range of solutions. The chapter argues that these address different aspects of the problem and that it is necessary to combine them and to give a stronger role to citizen activism to develop a more engaged politics in the UK. The approach to understanding the issues needs to embrace the full range of factors underlying the problem.

- In the final chapter, the relationship between social science and public policy is examined. The chapter argues for greater two-way engagement requiring more interplay between policy-makers and academics, and also greater willingness on the part of academics to consider the practical relevance of what they do.

Since the issues covered in the different chapters vary it is hard to generalise across them. Some common themes emerge, concerning the relationship between government and the other actors in public policy, individual citizens, the community and the market, and the way in which social science relates to public policy issues.

\section{State and civil society}

The chapters show how the dominant paradigms in each area may neglect evidence and theories so that policy debate passes over alternative approaches to the issues at stake. We suggest that more prominent state interventions are necessary to address many of the problems we discuss. A shift to a more liberal political economy offers a limited approach to the problem of restoring stable growth in the UK. There is no 
comprehensive solution to the problem of financing adequate public services under permanent austerity. A range of options must be combined and must also be acceptable to voters, which requires greater efforts to involve the public in the issues. Market policies such as carbon pricing have had little success in containing emissions at acceptable levels. A holistic and inclusive multiculturalism will not see the support of individuals and of communities as alternatives but will seek to promote an open social environment in which individuals can flourish in the kinds of communities that are meaningful to them. Government can manage population change in a more positive manner by enabling different generations to contribute. Localism and democratic empowerment depend on policies to address inequalities and to enable groups to contribute to the public good in the same way that multicultural policies as they are practised seek to do. Nudge economics can only succeed outside a limited area if government restrains the private commercial interests that are seeking to shape 'choice architecture'.

An emphasis on the role of government does not imply that these issues can be entirely resolved by central direction. Top-down interventions face limits to what they can achieve, and must be reinforced by bottom-up approaches resting on commitments in civil society. The relationship between state and individual citizen or local community is not a zero-sum game in which a loss of power by one automatically generates an equivalent gain by the other. Community initiatives and engaged citizenship require government support, especially for more vulnerable groups, and regulation to ensure that commercial interests are constrained.

These problems cut across many aspects of society. Just as social science must draw on the resources of a number of academic disciplines to understand them fully, so must policy-making integrate activities across agencies and across areas of government. The chapters review the contributions of political economy, social psychology, political sociology, demography, political science, social policy and historical studies to paradigm-building. They also show how adequate policy responses cannot be confined to the macro-level, but involve changes at the level of local government and in the way individuals and communities manage such issues as cultural difference, carbon footprints, the status of older people and their engagement with the political system.

\section{Social science and public policy}

The book demonstrates the twofold contribution of social science to public policymaking. Academic work can chart out the available viewpoints and show that it often contains a range of perspectives that is broader and richer than that dominant in policy debate. It can also contribute to identifying the policies that are likely to be most fruitful in managing the issues that confront us. Social scientists can also develop work consciously directed at policy design as well as analytic understanding in order to contribute to public policy-making.

We show how collaborative use of the repertoire of disciplinary approaches available across social science is essential in understanding issues that impact on different areas of social life and different aspects of policy. Corresponding to interdisciplinarity at the practical level, many of the issues require policy responses that link up different 
government departments, challenging existing structures at both central and local levels.

The final chapter considers the changes needed for social science to realise its contribution to practical policy-making: what are the implications for social science practise in developing a 'design arm' alongside the established academic focus? Scientific approaches foreground analysis, relate instances to more general categories and construct causal accounts. A design approach focuses more on synthetic thinking, cutting across different contexts. It is centrally concerned with achieving a given goal. The problem we identify is that a paradigm-driven political process risks neglecting some of the most valuable potential contributions of academic work when these are not included within the dominant paradigm.

Social science in the UK is excellent in its analytic and theoretical activities (by international comparisons), but less well directed to inform policy-making. One reason is that the current structure of social science as a professional activity does not highlight policy relevance. Another is that policy-making is not well adapted to survey the range of possible contributions that academic work could support. If social scientists wish their work to have greater impact in 'speaking truth to power', the onus is on the scientific community: it is necessary to produce additional work that draws on established research to engage more directly with the issues that confront policy-making.

\section{Conclusion}

In this book we set out arguments for an approach that indicates the range of ways of understanding the apparently intractable problems we currently face. We argue that those debating policy should pay much more attention to alternative paradigms than those currently dominant for thinking about many of these problems and should think through the implications of different approaches. The paradigms currently informing policy-making often fail to embrace the full range of evidence and understandings so that the problems are addressed from a limited range of perspectives.

The clearest example of this process is the way in which current approaches often diminish the role of government and conceptualise it as a simple alternative to that of civil society or of the individual citizen. The most influential paradigm presents government and non-government as alternatives, so that state activity is seen to crowd out the private sector or community provision or individual resourcefulness. The possibility that under appropriate circumstances state and civil society may walk in step, government stimulating and supporting initiatives in the community and in the private sector, receives limited attention. The possibilities for generating economic progress through more substantial government interventions receive scant attention. At the same time the potential for citizens and community to contribute to resolving problems is diminished because the capacity of top-down policy-making to support, interact with and strengthen bottom-up initiatives is ignored. The chapters show that the contribution of citizens in responding to diversity, in reducing carbon production, in improving community health and in tackling neighbourhood problems is potentially substantial, but that these benefits can only be fully realised with active government support. 
This book deals with some of the most pressing issues in public policy. We hope it will help draw attention to the contribution that social science has to make to current debates. It shows how a range of approaches from different disciplinary backgrounds can be combined to understand the way in which the issues under consideration will develop. It suggests that policy-makers need to consider a broader range of approaches in their work and to do so at the highest level, at the level of the policy paradigms that define their objectives, and also pick out particular aspects of what research has to offer. The book also argues that social science itself needs to develop to strengthen its policy contribution, by paying greater attention to the bounded and practical issues of policy design.

\section{References}

Hall, P. (1993) 'Policy Paradigms, Social Learning, and the State: The Case of Economic Policymaking in Britain', Comparative Politics, 25, 3, 275-296

Kuhn, T. (1962) The Structure of Scientific Revolutions, Chicago: University of Chicago Press. 